\title{
Observations and Simulation of a Bottom Ekman Layer on a Continental Shelf
}

\author{
T. D. DICKEY \\ Department of Geological Sciences, University of Southern California \\ J. C. VAN LeER \\ Rosenstiel School of Marine and Atmospheric Science, University of Miami

\begin{abstract}
A numerical model was used to simulate the bottom Ekman layer of a continental shelf region. The basis for the model was the Mellor and Yamada level $2 \frac{1}{2}$ turbulence closure scheme. Conservation equations for momentum, turbulent kinetic energy, and turbulent length scale were utilized in the model. The model was used to simulate data taken from a Cyclesonde mooring on the Peruvian continental shelf in May 1976 as part of the Joint 11 Coastal Upwelling Ecosystems Analysis program. The Cyclesonde provided mean horizontal velocity, temperature, salinity, and pressure data. An intense poleward undercurrent drove the bottom flow regime. The most striking feature of the data was the clockwise Ekman veering of velocity vectors as the bottom was approached. A 48-hour period was chosen for the model simulations. The vertical profile of speed (48 hours mean) simulated by the model fell within the error bars of the data. The corresponding Ekman spiral display of the model results also showed good agreement with the observations.
\end{abstract}

\section{INTRODUCTION}

The study of bottom boundary layers on continental shelves has been motivated by questions concerning frictional effects upon shelf circulation [e.g., Brink et al., 1978], sediment transport [e.g., Nowell, 1983], and coastal ecosystems [e.g., Rowe, 1981]. Several observations of the bottom boundary layer have been made on continental shelves in the past few years. Locations have included the west Florida shelf [e.g., Weatherly and Van Leer, 1977; Mercado and Van Leer, 1976], the Oregon shelf [e.g., Kundu, 1976; Huyer and Smith, 1978; Smith, 1981], the northwest African shelf [e.g., Smith, 1981], and the Peruvian shelf [e.g., Brink et al., 1978, 1980; Smith, 1981]. The feature common to virtually all of these studies has been Ekman veering near the bottom. The degree of veering and the vertical extent of the bottom boundary layers has varied, however.

The modeling of bottom flows on continental shelves has progressed substantially in recent years. Successful modeling efforts such as those by Smith and McLean [1977], Weatherly and Martin [1978], and Bird et al. [1982], have in fact stimulated the present study. The complexities of naturally occurring geophysical fluid dynamical regimes and/or insufficient data have often precluded the testing of models. Few studies have obtained high vertical resolution measurements of temperature, salinity, and velocity structure concurrently. Consequently, it has been difficult for theory to be compared with observations. The present work was motivated in large part by the availability of a data set which is unusually amenable to model simulation.

The focus of this study is the velocity structure of a bottom boundary layer; however, general reviews of the physical oceanographic observations taken during March-September 1976 at the JOINT II Coastal Upwelling Ecosystems Analysis (CUEA) site have been given by Brink et al. [1978] and Johnson [1981]. A mooring, Mila II, referenced in those works had

Copyright 1984 by the American Geophysical Union.

Paper number $3 \mathrm{C} 1717$.

0148-0227/84/003C-1717\$05.00 current meters located at depths of 33, 62, 84, and $109 \mathrm{~m}$. Its location was near the Cyclesonde mooring to be described.

\section{OBSERVATIONS}

The measurements to be described were taken off the coast of Peru as part of the Joint II CUEA program [ Van Leer and Ross, 1979] from May 27 to 29, 1976. The time period of the present study was limited on the basis of the criteria: (1) availability of continuous Cyclesonde records and (2) steadiness of the flow external to the bottom boundary layer. The site of the observations, $15.1^{\circ} \mathrm{S}$ and $75.5^{\circ} \mathrm{W}$ (C-27), and the bathymetric data provided by J. J. O'Brien are shown in Figure 1 . The slope angle is less than $0.5^{\circ}$ and the bottom is relatively smooth. A Cyclesonde (autonomous vertical profiler) provided mean horizontal velocity, temperature, salinity, and pressure data with a vertical resolution of $3 \mathrm{~m}$. Data were vertically averaged in $5 \mathrm{~m}$ bins. Details concerning the Cyclesonde may be found in Van Leer [1974, 1976]. Relevant rms error estimates for absolute speed and direction accuracy are $\pm 1 \mathrm{~cm} / \mathrm{s}$ and $\pm 3^{\circ}$, respectively.

The Cyclesonde mooring (C-27) was located in water of 100 m depth approximately $4.5 \mathrm{~km}$ offshore. Two profiles were taken each hour to within $3 \mathrm{~m}$ of the bottom. Data were recorded within the Cyclesonde and were transmitted in real time to a surface buoy mounted transmitter. Data were received and recorded on shipboard and later were transmitted by satellite to Miami for processing. A Cyclesonde mooring is illustrated in Figure 2.

The bottom flow over the Peruvian continental shelf during the period of interest was driven by a poleward undercurrent which was predominantly along isobaths. This is confirmed by other data taken by Brink et al. [1978]. The core of the undercurrent generally had maximum speeds ranging between 30 and $50 \mathrm{~cm} \mathrm{~s}^{-1}$. The core was located approximately $12 \mathrm{~km}$ offshore and was centered at about $100 \mathrm{~m}$ below the surface. The undercurrent appeared to extend to within $1-3 \mathrm{~km}$ of the shore and down to the bottom boundary layer. An average onshore flow of about $5 \mathrm{~cm} / \mathrm{s}$ (above bottom boundary layer) was observed, and transport was offshore within the bottom boundary layer. Occasional periods of wind-driven upwelling 


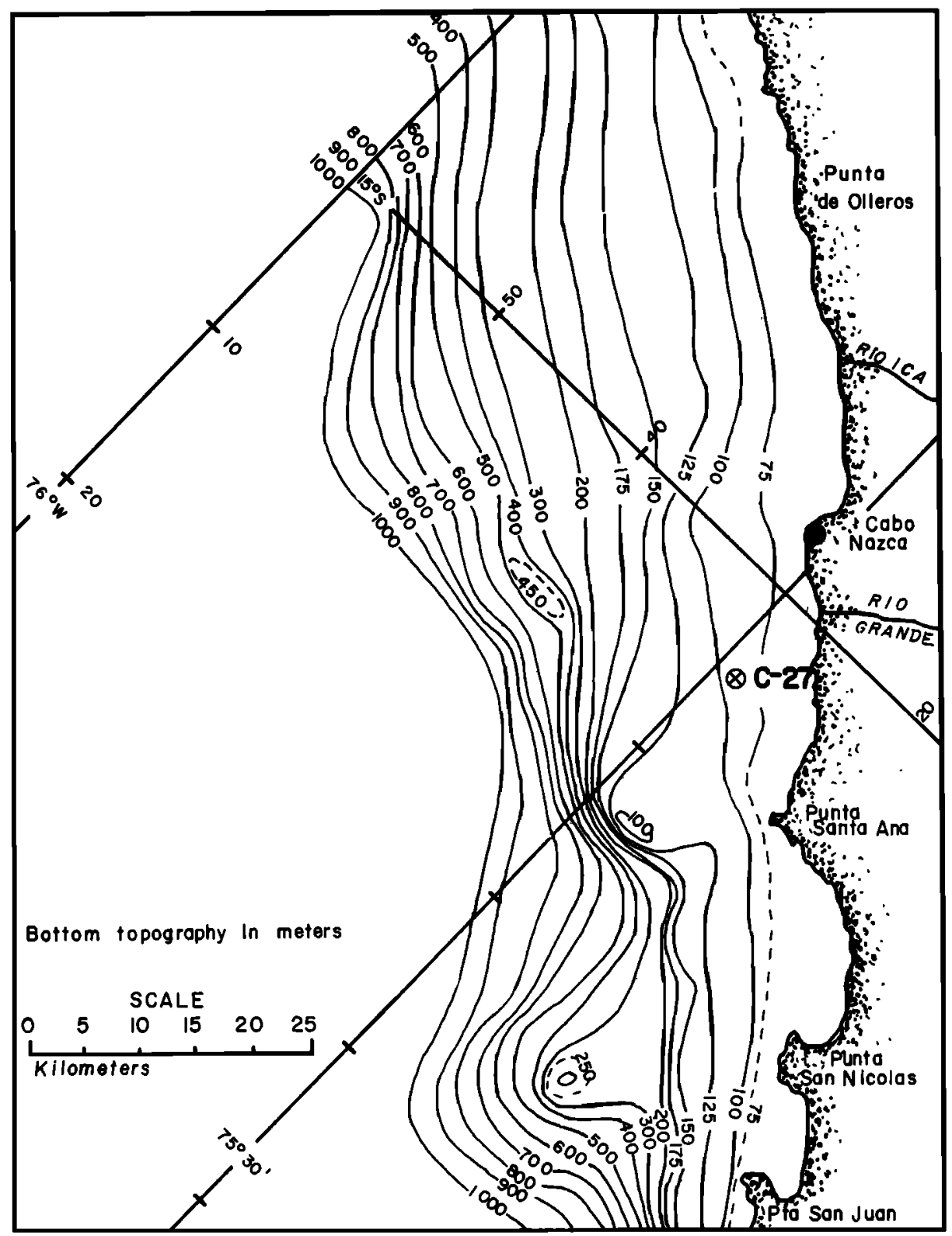

Fig. 1. Bottom topography of Joint II CUEA region off the coast of Peru (after J. J. O'Brien). Isobaths are in meters. C-27 indicates the site of the Cyclesonde mooring used for the present study.

or downwelling often coincide with local wind events. However, local wind forcing was apparently not important in establishing the mean interior flow which was steady for the period of interest (a wind event occurred subsequently). The salinity was nearly constant in time and uniform in space; thus, density variation was dominated by temperature changes. Information concerning the horizontal physical structure which was derived from the complete set of observations may be found in Van Leer and Ross [1979] and Johnson [1981]. In addition, Preller and O'Brien [1980] have utilized a two-layer primitive equation model to investigate circulation during the period.

The Cyclesonde temperature data were compiled as time series at several depths. These series indicated that temperature was nearly steady state with only a slight increase in temperature within the lower $35 \mathrm{~m}$. The 48 -hour mean vertical profile of temperature is shown in Figure 3. The stratification in the region more than $35 \mathrm{~m}$ above the bottom exceeded by more than 5 times that within $35 \mathrm{~m}$ of the bottom. The Brünt-Väisälä frequency squared $\left(N^{2}\right)$ for the bottom $35 \mathrm{~m}$ was $1.9 \times 10^{-5} \mathrm{~s}^{-2}$. Weatherly and Van Leer [1977] have defined bottom homogeneous layers as regions where vertical gradients in temperature are less than $0.10^{\circ} \mathrm{C} / 5 \mathrm{~m}$. A value of $0.04^{\circ} \mathrm{C} / 5 \mathrm{~m}$ was obtained for the bottom $35 \mathrm{~m}$ of the present data, which indicates that a bottom homogeneous layer existed. A dynamic parameter relevant to flow stability is the layer Richardson number, $R i_{L}=N^{2} /(\text { shear) })^{2} . R i_{L}$ was computed as a function of depth and time from the data. The vertical resolution, $\Delta z=5 \mathrm{~m}$, used for computation of $N^{2}$ and shear, is quite coarse and hence leads to higher values than those derived from the more conventional gradient Richardson numbers [see Evans, 1982]. Nonetheless, over two thirds of the $R i_{L}$ values within the bottom $35 \mathrm{~m}$ were less than 1 . Above the bottom $35 \mathrm{~m}$, however, $R i_{L}$ was almost always considerably greater than 1 . There was consequently a barrier to mixing beginning at about $35 \mathrm{~m}$ above the bottom. The depth 


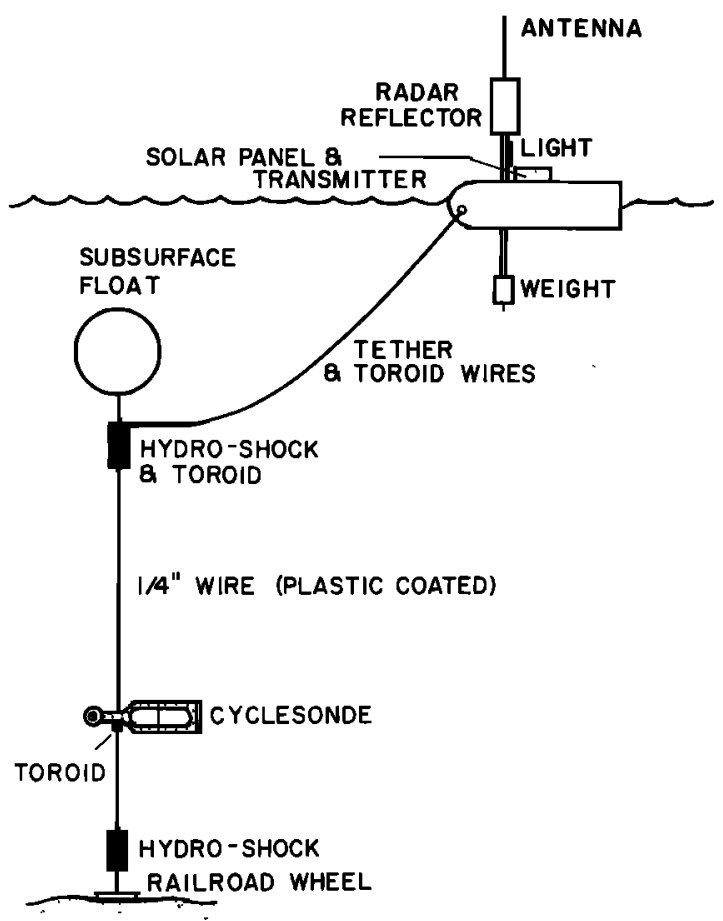

Fig. 2. Cyclesonde mooring used during the field program.

of transition between the two regions was nearly invariant with time throughout the 48 -hour period. The speed time series was averaged over the 48-hour period resulting in the vertical profile shown in Figure 4. A shear zone may be seen in the region of transition at $65 \mathrm{~m}$ depth. The observations are displayed in the classical Ekman layer plan view of Figure $5 a$. Once again it is apparent that the bottom boundary layer extended to about $35 \mathrm{~m}$ above the bottom. The veering was relatively uniform with depth, and the veer angle was $23^{\circ}$ between depths of 65 and $95 \mathrm{~m}$. The data of Brink et al. [1978] for the Mila II mooring indicate slightly less veering on the

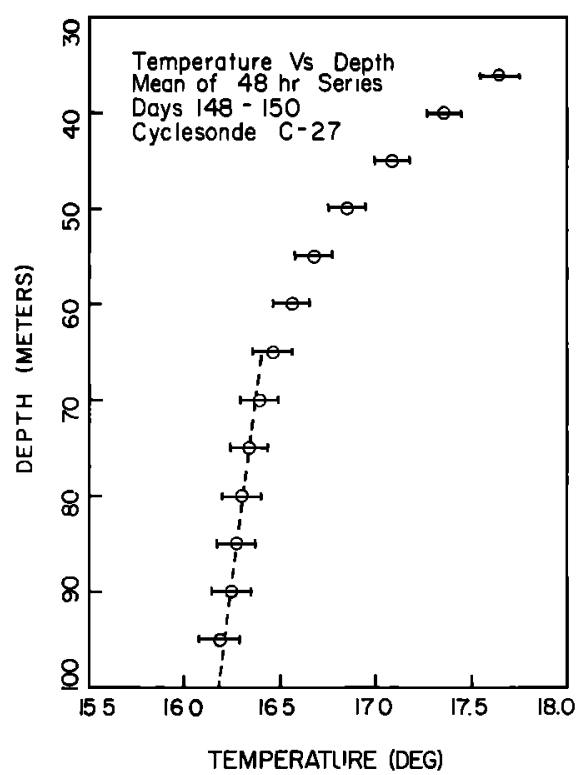

Fig. 3. Vertical profile of the 48-hour mean temperature. Dashed line is a fit to data. Error bars indicate manufacturer's specification of temperature accuracy. basis of a 72-day mean; however, a direct determination of the bottom boundary layer depth was not possible for their data set.

The thickness of the bottom boundary layer has often been estimated by the relation

$$
h=0.4 \frac{u_{*}}{|f|}
$$

[e.g., Wimbush and Munk, 1970; Weatherly, 1972] where $u_{*}$ is the friction velocity estimated by $0.03 G$ to $0.05 G$ [e.g., Weatherly et al., 1980], where $G$ is the geostrophic speed outside the boundary layer and $f=-3.8 \times 10^{-5} \mathrm{~s}^{-1}$ is the Coriolis parameter. Using $G=24 \mathrm{~cm} / \mathrm{s}$ for the present data, values of $h=76-127 \mathrm{~m}$ are obtained. Weatherly and Martin [1978] have forwarded the following expression for the boundary layer thickness which accounts for stratification outside the bottom boundary layer

$$
h=\frac{1.3 u_{*}}{|f|\left[1+N_{0}{ }^{2} /|f|^{2}\right]^{1 / 4}}
$$

where $N_{0}$ is the Brünt-Väisälä frequency above the bottom boundary layer. Choosing $N_{0}^{2}=1 \times 10^{-4} \mathrm{~s}^{-2}$ as a representative value in the interior and substituting other values appropriate for the present data, $h$ varies in the range $16-26$ m. Weatherly and Martin [1978] have cautioned that their expression may be invalid for $N_{0} /|\dot{f}|>200$. The present value of $N_{0} /|f|$ is about 260 . The latter formula for $h$ gives more reasonable estimates than equation (1), but, as specified by Weatherly and Martin [1978], the parameter range of validity has been exceeded. One would expect reduced bottom boundary layer thicknesses for greater values of $N_{0}$ as argued by Weatherly and Martin [1978].

\section{Simulation}

The present study utilized the level $2 \frac{1}{2}$ version of the Mellor and Yamada [1974] turbulence closure scheme [e.g., Blumberg and Mellor, 1981; Mellor and Yamada, 1982]. This model and

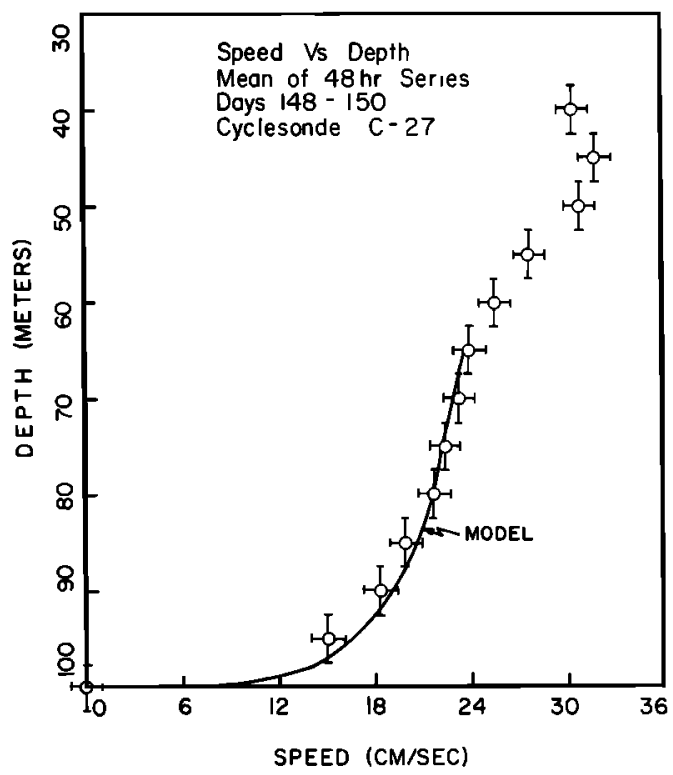

Fig. 4. Observed 48 hour mean vertical profile of speed. Error bars were estimated from manufacturer's specifications for speed and vertical averaging of $5 \mathrm{~m}$. Modeled 48 hour mean vertical profile of speed is shown with a solid curve. 


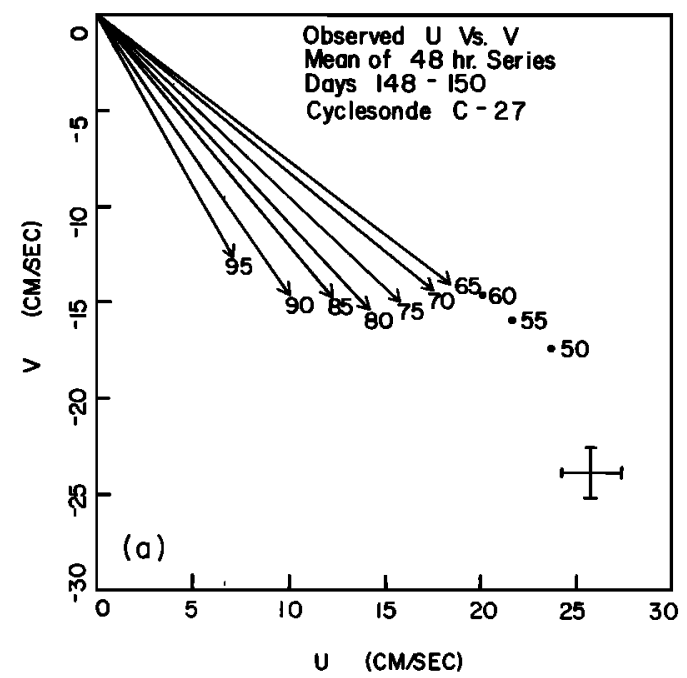

Fig. 5a. Observed mean zonal velocity versus mean meridional velocity. Velocity error bars reflect absolute speed and directional accuracy as well as uncertainty due to vertical spatial averaging.

its slightly simpler counterpart, level 2 version, have been relatively successful in simulating atmospheric and oceanic data [e.g., Mellor, 1973; Mellor and Durbin, 1975; Worthem and Mellor, 1980; Clancey and Martin, 1981; Warn-Varnas et al., 1981; Martin, 1982]. More specifically, the level 2 version was used by Weatherly and Martin [1978] to simulate bottom boundary layer data taken with a Cyclesonde on the west Florida continental shelf [Weatherly and Van Leer, 1977]. Bird et al. [1982] have also used this model for a study of the bottom boundary layer over the eastward scarp of the Bermuda Rise. Mellor and Yamada [1982] have indicated that the level $2 \frac{1}{2}$ version of the model has a greater predictive range than the level 2 version and that the macro-length scale equation of level $2 \frac{1}{2}$ seems to be superior to the algebraic length scale equation of level 2 . For these reasons, the level $2 \frac{1}{2}$ version seemed appropriate for the present study. The details of the model have been described by Blumberg and Mellor [1981] and Mellor and Yamada [1982]. A brief description of the model follows.

The mean zonal and meridional momentum equations may be written as

$$
\frac{\partial U}{\partial t}-f\left(V-V_{\theta}\right)=\frac{\partial}{\partial z}(-\overline{w u})
$$

and

$$
\frac{\partial V}{\partial t}+f\left(U-U_{\theta}\right)=\frac{\partial}{\partial z}(-\overline{w v})
$$

where $z$ is the vertical coordinate, $t$ is time, $U$ and $V$ are the mean zonal and meridional velocity components, $U_{g}$ and $V_{g}$ are the corresponding geostrophic velocity components, and $-\overline{w u}$ and $-\overline{w v}$ are the vertical turbulent Reynolds stresses. Incompressibility is assumed, and all mean advection terms have been neglected. Boundary layer scaling leads to the omission of horizontal gradient terms. The primary motivation of the present study was to model the bottom velocity structure. On the basis of the observations and evaluation of $N^{2}$ and $R i_{L}$ described earlier, the bottom boundary layer (bottom $35 \mathrm{~m}$ ) was modeled as a homogeneous turbulent flow. Hence, heat exchange and buoyancy effects have been neglected. The cross-shelf isotherm slope relative to the bottom appeared to be small for the observational period, and, hence, inclined bottom effects have not been included [see Bird et al., 1982]. The key Reynolds stress terms may be written in the classical eddy viscosity form

$$
-\overline{w u}=K_{M} \frac{\partial U}{\partial z}=q S_{M} \frac{\partial U}{\partial z}
$$

and

$$
-\overline{w v}=K_{M} \frac{\partial V}{\partial z}=q l S_{M} \frac{\partial V}{\partial z}
$$

where $K_{M}$ is a turbulence dependent eddy viscosity, $q$ is the square root of twice the turbulent kinetic energy, and $l$ is the turbulent macro-length scale which is proportional to the integral length scale. $S_{M}$ is a form function which is dependent upon the turbulence; its expression follows from closure hypotheses. The value of $S_{M}$ for the present simulations was nearly constant and equal to 0.4 . The equation for turbulent kinetic energy, $T K E=q^{2} / 2$, is given by

$$
\frac{\partial q^{2} / 2}{\partial t}=\frac{\partial}{\partial z}\left[q l S_{q} \frac{\partial}{\partial z}\left(q^{2} / 2\right)\right]+P_{s}-\varepsilon
$$

where $S_{q}$ is a stability function equal to $0.051 S_{M}, P_{s}$ is shear production given by

$$
P_{s}=-\overline{w u} \frac{\partial U}{\partial z}-\overline{w v} \frac{\partial V}{\partial z}
$$

and $\varepsilon$ is the dissipation rate or

$$
\varepsilon=\frac{q^{3}}{B_{1} l}
$$

where $B_{1}=16.6$ is an empirical constant whose value is based upon laboratory data [Mellor and Yamada, 1982]. The turbulence macro-length scale equation is

$$
\frac{\partial\left(q^{2} l\right)}{\partial t}=\frac{\partial}{\partial z}\left[q l S_{q} \frac{\partial\left(q^{2} l\right)}{\partial z}\right]+E_{1} l P_{s}-\frac{q^{3} W}{B_{1}}
$$

and $W$ is a wall function given by

$$
W=1+E_{2}\left[\frac{l}{\kappa L}\right]^{2}
$$

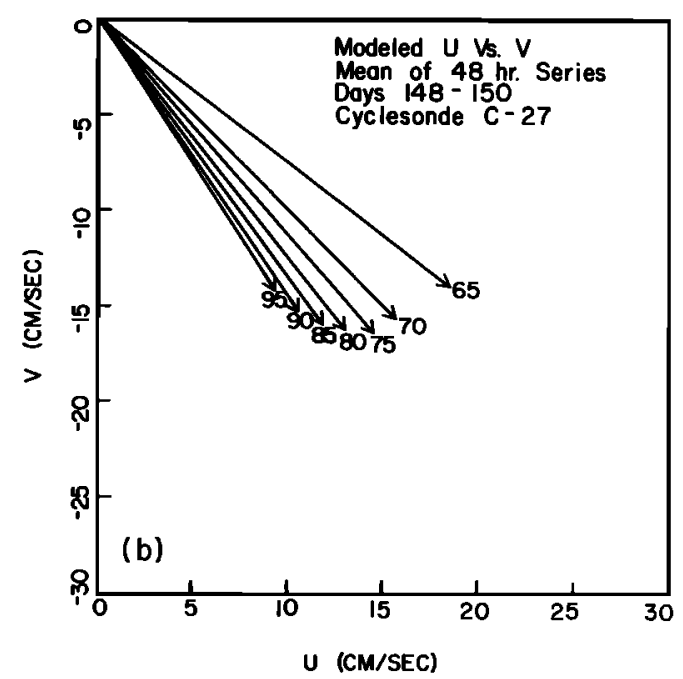

Fig. 5b. Modeled mean zonal velocity versus mean meridional velocity. Depths in meters are indicated. 
The values of empirical constants $E_{1}$ and $E_{2}$ (1.8 and 1.33, respectively) are based upon laboratory data [Mellor and Yamada, 1982] and $\kappa=0.40$ is the von Karman constant. The wall proximity length, $L$, is evaluated from

$$
\frac{1}{L}=\frac{1}{z-d}+\frac{1}{D-z}
$$

where $D=100 \mathrm{~m}$ is water depth and $D-d=35 \mathrm{~m}$ is the vertical extent of the modeled flow. In the vicinity of a boundary, $l$ and $L$ are proportional to the distance from the boundary. Note that $W \rightarrow 1$ far from boundaries because $L \gg l$. The macro-length scale is based upon the integral of the two-point correlation function. The macro-length scale closure assumptions are more difficult to support than the others. Nonetheless, using this form several simulations of turbulent flows have been shown to be in good agreement with experimental data [Mellor and Yamada, 1982]. It should be noted that (aside from the roughness parameter which must be chosen on the basis of the bottom environment or data) only laboratoryderived empirical constants are utilized in the turbulence model. Hence, no empirical constants have been adjusted for the present simulation.

The general numerical scheme is described by Blumberg and Mellor [1981]. The present simulation utilized 41 vertical computational grid points for the simulated region. The distribution of the grid points was logarithmic in order to optimize the resolution near the bottom, and the coarsest spacing was 1 $\mathrm{m}$. The computational time step was 1 hour and the duration of the run was 96 hours to assure that a steady state condition was achieved. The flow was driven by a constant geostrophic current taken from the data at $35 \mathrm{~m}$ above the bottom. To minimize inertial oscillations, the geostrophic current at $65 \mathrm{~m}$ depth was initiated with a ramp function (time) for an inertial period as suggested by Weatherly and Martin [1978]. The finite difference mean velocity boundary condition is given by

$$
\left(U_{1}, V_{1}\right)=\left(U_{2}, V_{2}\right) \frac{\ln \left[\left(D-z_{1}\right) / z_{0}\right]}{\ln \left[\left(D-z_{2}\right) / z_{0}\right]}
$$

where subscript 1 refers to the grid point nearest the bottom and 2 refers to the next higher grid point and $z_{0}$ is the velocity roughness parameter [Yamada and Mellor, 1975]. Unfortunately, evaluation of $z_{0}$ from Cyclesonde data was precluded because the measurements were only to within $3 \mathrm{~m}$ of the bottom and thus outside the logarithmic layer. However, a free-drop camera was used to photograph the bottom which was characterized by fine silt sediment with roughness relief, $\delta$, estimated to be less than $1 \mathrm{~cm}$. Hence, utilizing the expression $z_{0}=\delta / 30$ [e.g., Wimbush and Munk, 1970] a value of $z_{0}=0.03$ $\mathrm{cm}$ was used for the primary simulation described here.

The modeled speed profile is shown in Figure 4. The model results fall within the estimated rms error levels of the Cyclesonde. Observations and model results are shown in plan views of the velocity vectors in Figure 5 . The observed veering between depths of 65 and $95 \mathrm{~m}$ is about $23^{\circ}$ compared with approximately $20^{\circ}$ for the model. The difference between these two angles is comparable to overall directional accuracy of the Cyclesonde. The veering is dependent upon the model eddy viscosity which is shown in Figure 6. The functional form has minimum values at the bottom and top of the boundary layer and a maximum value about midway. The turbulent kinetic energy decreases with distance above the bottom where shear production is maximum. The macro-length scale increases

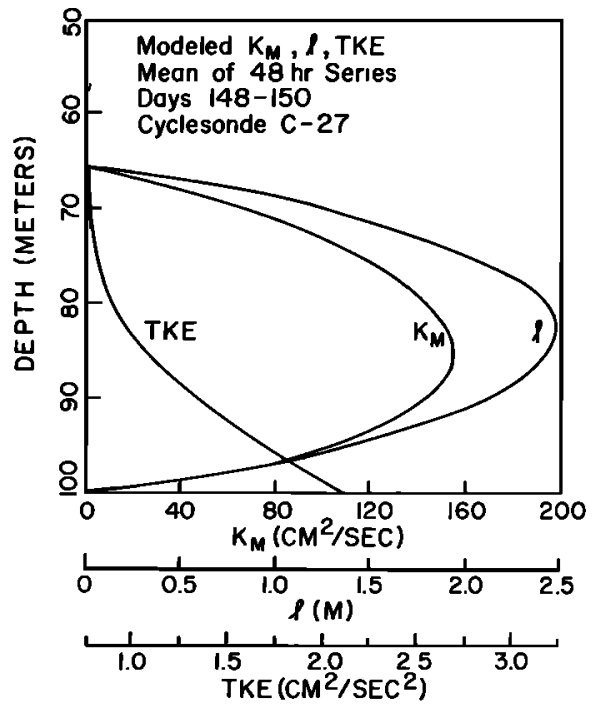

Fig. 6. Modeled values of eddy viscosity, turbulent kinetic energy, and macro-length scale versus depth.

with distance from the bottom and from the top of the bottom homogeneous layer. This is consistent with the concept that eddy size increases with distance away from boundaries and turbulence sources. The modeled eddy viscosity may be somewhat too low near the top of the boundary layer because of underestimated momentum flux and slightly too high in the interior portion of the boundary layer because of the homogeneity assumption.

Bottom stress was computed by applying equations (5) and (6) near the bottom. The magnitude of the modeled bottom stress is 0.69 dynes $/ \mathrm{cm}^{2}$ and the direction is $-57.4^{\circ}$ true or $20.4^{\circ}$ to the right of the geostrophic velocity vector at $65 \mathrm{~m}$. Unfortunately, it is not possible to make comparable estimates of bottom stress from the present data set. Another important parameter is the drag coefficient, $C_{100}$, based upon the velocity $100 \mathrm{~cm}$ above the bottom. The model predicts a value of $3.4 \times 10^{-3}$ which is in the range of values $\left(10^{-3}\right.$ to $10^{-2}$ with mean $3.1 \times 10^{-3}$ ) reported by Sternberg [1968]. The friction velocity is $0.82 \mathrm{~cm} / \mathrm{s}$ or $u_{*} / G=0.035$ which is in the range 0.03-0.05 commonly observed [e.g., see Weatherly et al., 1980].

\section{Discussion}

A number of competing factors which contribute to the momentum flux are present in the actual geophysical environment [e.g., Nowell, 1983]. Not all of these have been considered for the present study. The period of model simulation was chosen such that a relatively simple, though geophysically relevant, flow state existed. However, tidal, internal and inertial wave, and advective motions were present in varying degrees [Johnson, 1981]. Therefore, model test cases were also driven with the hourly mean velocity at $65 \mathrm{~m}$ depth in order to examine the effects of time varying external flow. Little difference between the 48-hour mean and hourly mean driving resulted (e.g., $2 \%$ difference in speed).

Another relevant question concerns flow sensitivity to $z_{0}$. Model runs were done with values of $z_{0}$ ranging up to 1.00 $\mathrm{cm}$. Differences of less than $5 \%$ in speed and veering angle resulted. However, bottom stress was greater for $z_{0}=1.00 \mathrm{~cm}$ $\left(0.87\right.$ dynes $\left./ \mathrm{cm}^{2}\right)$ than for $z_{0}=0.03 \mathrm{~cm}\left(0.69 \mathrm{dynes} / \mathrm{cm}^{2}\right)$. This is consistent with the fact that the value of $C_{100}$ was significantly greater for $z_{0}=1.00 \mathrm{~cm}$ than for $z_{0}=0.03 \mathrm{~cm}\left(C_{100}=\right.$ 
$6.4 \times 10^{-3}$ compared with $C_{100}=3.4 \times 10^{-3}$ ). These values still fall within the range reported by Sternberg [1968] and agree with general trends between $z_{0}$ and $C_{100}$ shown by Sternberg [1972].

Other simpler turbulence parameterization schemes are available. For intercomparison, the level $2 \frac{1}{2}$ closure scheme was replaced in the model with a constant eddy viscosity closure [e.g., see Kraus, 1972, chapter 6]. Values of $K_{M}$ equal to $50-150 \mathrm{~cm}^{2} / \mathrm{s}$ were used. These simulations underestimated speed and overestimated veering with values generally lying outside experimental error limits. It is clear that vertically varying eddy viscosity is an essential element for bottom velocity prediction.

The evaluation of the general applicability of second moment turbulence closure models will require simulations of less restrictive data sets. High vertical resolution time series of velocity must be done simultaneously within the logarithmic layer and the bottom Ekman layer in order to test the ability of the model to predict bottom stress. At present, turbulence closure models applied to the bottom boundary layer do not explicitly account for inertial or internal wave interaction with the bottom boundary layer or coherent structures and intermittency. Nonetheless, the present results along with those obtained by other investigators demonstrate the utility of second moment turbulence closure models when applied to the bottom boundary layer.

Acknowledgments. Special thanks are due D. S. Gorsline and J. D. Smith who suggested a modeling study of the bottom boundary layer. A. F. Blumberg and A. W. Bratkovich provided valuable suggestions which led to an improved manuscript. The field work was supported by NSF/IDOE CUEA grant OCE-7827107 and OCE-7800604 and the modeling was supported by NSF grant OCE-8001709. This manuscript was typed by Michael Lane.

\section{REFERENCES}

Bird, A. A., G. L. Weatherly, and M. Wimbush, A study of the bottom boundary layer over the eastward scarp of the Bermuda Rise, $J$. Geophys. Res., 87, 7941-7954, 1982.

Blumberg, A. F., and G. L. Mellor, A coastal ocean numerical model, Mathematical Modeling of Estuarine Physics, edited by J. Sundermann and K. P. Holz, pp. 203-219, Springer-Verlag, New York, 1981.

Brink, K. H., J. S. Allen, and R. L. Smith, A study of low-frequency fluctuations near the Peru coast, J. Phys. Oceanogr., 8, 1025-1041, 1978.

Brink, K. H., D. Halpern, and R. L. Smith, Circulation in the Peruvian upwelling system near $15^{\circ} \mathrm{S}, J$. Geophys. Res., 85, 4036-4048, 1980.

Clancey, R. M., and P. J. Martin, Synoptic forecasting of the oceanic mixed layer using the Navy's operational environmental data base: Present capabilities and future applications, Bull. Am. Meteorol. Soc., 62, 770-784, 1981.

Evans, D. L., Observations of small-scale shear and density structure in the ocean, Deep Sea Res., 29, 581-595, 1982.

Huyer, A., and R. L. Smith, Seasonal differences in low-frequency current fluctuations over the Oregon continental shelf, J. Geophys. Res., 83, 5077-5089, 1978.

Johnson, W. R., The propagation of inertial-internal waves in coastal upwelling regions, Ph.D. thesis, Univ. of Miami, Miami, Fla., 1981.

Kraus, E. B., Atmosphere-Ocean Interaction, Clarendon, Oxford, 1972.

Kundu, P. K., Ekman veering observed near the ocean bottom, J. Phys. Oceanogr., 6, 238-242, 1976.

Martin, P. J., Mixed-layer simulation of buoy observations taken during Hurricane Eloise, J. Geophys. Res., 87, 409-427, 1982.

Mellor, G. L., Analytic prediction of the properties of stratified planetary surface layers, J. Atmos. Sci., 30, 1061-1069, 1973.

Mellor, G. L., and P. A. Durbin, The structure and dynamics of the ocean surface mixed layer, J. Phys. Oceanogr., 5, 718-728, 1975.
Mellor, G. L., and T. Yamada, A hierarchy of turbulence closure models for planetary boundary layers, J. Atmos. Sci., 31, 17911806, 1974.

Mellor, G. L., and T. Yamada, Development of a turbulence closure model for geophysical problems, Rev. Geophys. Space Phys., 20, 851-875, 1982.

Mercado, A., and J. Van Leer, Near bottom velocity and temperature profiles observed by Cyclesonde, Geophys. Res. Lett., 3, 633-636, 1976.

Nowell, A. R. M., The benthic boundary layer and sediment transport, Rev. Geophys. Space Phys., 21, 1181-1192, 1983.

Preller, R., and J. J. O'Brien, The influence of bottom topography on upwelling off Peru, J. Phys. Oceangr., 10, 1377-1398, 1980.

Rowe, G. T., The benthic processes of coastal upwelling ecosystems, in Coastal Upwelling, edited by F. A. Richards, pp. 464-472, AGU, Washington, D.C., 1981.

Smith, J. D., and S. R. Mclean, Boundary layer adjustments to bottom topography and suspended sediment, in Bottom Turbulence, edited by J. C. J. Nihoul, pp. 123-151, Elsevier, New York, 1977.

Smith, R. L., A comparison of the structure and variability of the flow field in three coastal upwelling regions: Oregon, northwest Africa, and Peru, in Coastal Upwelling, edited by F. A. Richards, pp. 107118, AGU, Washington, D. C., 1981.

Sternberg, R. W., Friction factors in tidal channels with differing bed roughness, Mar. Geol., 6, 243-260, 1968.

Sternberg, R. W., Predicting initial motion and bedload transport of sediment particles in the shallow marine environment, in Shelf Sediment Transport, edited by D. J. P. Swift, D. B. Duane, and O. H. Pilkey, pp. 61-82, Dowden, Hutchinson, and Ross, Stroudsburg, Pa., 1972.

Van Leer, J. C., Progress report on Cyclesonde development and use, UM-RSMAS, 74029, Univ. of Miami, Miami, Fla., 1974.

Van Leer, J. C., An automatic oceanographic profiling instrument, paper presented at 22nd International Instrumentation Symposium, Instrument Society of America, San Diego, Calif., May 25-27, 1976.

Van Leer, J. C., and A. E. Ross, Velocity and temperature data observed by Cyclesonde during Joint II off the coast of Peru, CUEA Data Rep. 61, RSMAS Data Rep. DR79-2, Univ. of Miami, Miami, Fla., 1979.

Warn-Varnas, A. C., G. M. Dawson, and P. J. Martin, Forecast and studies of the oceanic mixed layer during the MILE experiment, Geophys. Astrophys. Fluid Dyn., 17, 63-85, 1981.

Weatherly, G. L., A study of the bottom boundary layer of the Florida current, J. Phys. Oceanogr., 2, 54-72, 1972.

Weatherly, G. L., and P. J. Martin, On the structure and dynamics of the oceanic bottom boundary layer, J. Phys. Oceanogr., 8, 557-580, 1978.

Weatherly, G. L., and J. C. Van Leer, On the importance of stable stratification to the structure of the bottom boundary layer on the western Florida shelf, in Bottom Turbulence, edited by J. C. J. Nihoul, pp. 103-112, Elsevier, New York, 1977.

Weatherly, G. L., S. L. Blumsack, and A. Bird, On the effect of diurnal tidal currents in determining the thickness of the turbulent Ekman bottom boundary layer, J. Phys. Oceanogr., 10, 297-300, 1980.

Wimbush, M., and W. Munk, The benthic boundary layer, in The Sea, vol. 4, edited by A. E. Maxwell, pp. 731-758, John Wiley, New York, 1970.

Worthem, S., and G. L. Mellor, Turbulence closure model applied to the upper tropical ocean, Deep Sea Res., 26 (suppl), 237-272, 1980.

Yamada, T., and G. Mellor, A simulation of the Wangara atmospheric boundary layer data, J. Atmos. Sci., 32, 2309-2329, 1975.

T. D. Dickey, Department of Geological Sciences, University of Southern California, Los Angeles, CA 90089.

J. C. Van Leer, Rosentiel School of Marine and Atmospheric Science, University of Miami, 4600 Rickenbacker Causeway, Miami, FL 33149.

(Received August 16, 1982;

revised August 12, 1983;

accepted October 24, 1983.) 